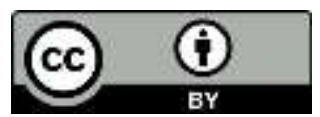

\title{
TAI CHI CHUAN: O COMBATE AO DUALISMO PELA EXPERIÊNCIA MÍSTICA DO SAGRADO
}

\author{
Tai Chi Chuan: The Combat Against Dualism Through the Mystical Experience of The Sacred
}

\author{
Michelle Suzana de Almeida Gabani \\ Psicóloga, Especialista em Psicologia Transpessoal \\ Mestranda do PPG em Psicologia Clínica - UFPR Bolsista Capes \\ $\underline{\text { contato@ michellegabani.com.br }}$
}

\begin{abstract}
RESUMO: O objetivo do artigo é demonstrar como o tai chi chuan, arte marcial chinesa voltada para o cultivo da energia interior (chi), pode ser compreendida como uma metáfora psíquica alquímica de unificação da dualidade a partir da replicação ritualística da cosmogonia chinesa implícita na técnica, proporcionando a reconexão do praticante com seu self. No Brasil é cada vez mais nítido o interesse pelo pensamento e a filosofia oriental expressado pelo fomento da prática no âmbito das políticas públicas de saúde e que decorre de uma preocupação em escala mundial com valores de cunho cada vez mais humanitários, ecológicos, anímicos, que paulatinamente insinuam-se em meio ao modus vivendi materialista. $\mathrm{O}$ tema foi desenvolvido a partir da revisão bibliográfica baseada principalmente nos conceitos da psicologia analítica de C.G. Jung e da noção de sagrado de M. Eliade. Conclui-se que o tai chi chuan é uma arte marcial que traz em seu bojo uma metáfora alquímica capaz de proporcionar o surgimento de um espaço psíquico e sagrado interno no praticante ocidental a partir da repetição dos movimentos, da vivência de sua circularidade e simbologia, reproduzindo o pensamento místico cosmogônico chinês de retorno ao seu princípio fundamental unificador de todas as coisas (Taiji).

Palavras-chave: Tai chi chuan; Alquimia; Sagrado; Místico.
\end{abstract}

ABSTRACT: The aim of the paper is to demonstrate how tai chi chuan, chinese martial art focused on the cultivation of internal energy (chi), can be understood as a metaphor for psychic alchemical unification of duality from the ritualistic replication of chinese cosmogony implied in technique, providing reconnection the practitioner with his self. In Brazil it is increasingly clear the interest in thought and Eastern philosophy expressed by fostering practice within public health policies and that stems from a concern on a global scale with values imprint increasingly humanitarian, ecological, psychic, who gradually insinuate themselves amidst the modus vivendi materialistic. The theme was developed from the literature review mainly based on the concepts of analytical psychology of C.G. Jung and the sacred notion of M. Eliade. It is concluded that tai chi chuan is a martial art that brings with it an alchemical metaphor able to provide the creation of an internal psychic and sacred space in the Western practitioner from the repetition of movements, the experience of its circularity and symbology, reproducing the mystical chinese cosmogonic thought back to the fundamental unifying principle of all things (Taiji).

Keywords: Tai chi chuan; Alchemy; Sacred; Mystic. 


\section{Introdução}

O tai chi chuan $^{1}$, o yoga em suas diversas modalidades, a acupuntura, a medicina chinesa, a medicina ayurvédica, etc., enfim, o pensamento e o misticismo oriental expresso em diversas técnicas que no Brasil são classificadas como terapias integrativas, alternativas ou complementares, estão ganhando cada vez mais adeptos, inclusive por membros das alas mais ortodoxas da moderna ciência contemporânea.

As descobertas científicas, a racionalização do pensamento e sua desvinculação da Igreja deram início ao processo de secularização, que afastou a cegueira provocada pelo dogmatismo religioso e permitiu avanços tecnológicos sequer antes imaginados. No entanto, o modus vivendi contemporâneo facilita a manifestação e amplificação de transtornos psíquicos que, com o tempo, alcançam o nível somático. O homem encontra-se formatado para o trabalho e o consumo em um processo vicioso que se retroalimenta de modo frenético em um mundo cada vez mais dessacralizado, como aduz Eliade [198-]. Sua existência torna-se banalizada na medida em que é programado desde a mais tenra idade a se transformar em um autômato, que trabalha e consome exaustivamente para manter o status quo imposto pelo paradigma atuante. Esse panorama torna a existência humana extremamente empobrecida, carente de sentido, que propicia a gênese de psicopatologias que dão sentido à seguinte expressão: "o excesso de animalidade deforma o homem cultural; o excesso de cultura cria animais doentes" (JUNG, 2007, p. 20).

Segundo o Secretário Geral da Organização das Nações Unidas (ONU) em mensagem divulgada no Dia Mundial da Saúde Mental de 10/10/2012, "cerca de 350 milhões de pessoas de todas as idades, níveis de rendimento e nacionalidade sofrem de depressão" e que cerca de um milhão cometem suicídio a cada ano, a grande maioria em razão dessa doença. Para a ONU, trata-se de uma psicopatologia que já alcançou o status de crise global e que implica em imediatas ações de intervenções psicossociais e medicamentosas.

\footnotetext{
${ }^{1}$ Através do antigo sistema de romanização Wade-Giles criado nos anos de 1950, a técnica passou a ser transliterada como tai chi chuan, a forma mais comumente encontrada no Brasil. As variações Taijiquan ou TaiJi Quan são decorrentes do sistema oficial de transliteração denominado PinYin e poderão ser mencionados no texto de uma ou outra forma a critério dos autores citados.

${ }^{2}$ UNRIC. Centro Regional das Nações Unidas: Mensagem do Secretário Geral da ONU no Dia Mundial da Saúde Mental, 10 de Outubro de 2012. Disponível em <http://www.unric.org/pt/mensagens-do-secretariogeral/30942-mensagem-do-secretario-geral-da-onu-no-dia-mundial-da-saude-mental-10-de-outubro-de-2012>. Acesso em: 16 out. 2012.
} 
Porém, esse modelo paradigmático em voga, notadamente patriarcal e cartesiano, ensejador de tantas psicopatologias, começa a demonstrar sinais de arrefecimento, permitindo a emersão de um novo modelo de pensamento. Um pensar ecocêntrico, que valoriza a vida em todas as suas manifestações e que tira o homem da sua posição de dominador e explorador inconsequente da natureza, vem lentamente permitindo a inclusão de novos hábitos. O empobrecido homem ocidental está começando a experienciar, transitar, usufruir e descobrir novas dimensões de si mesmo a partir de uma perspectiva holística que o enxerga cada vez mais como um ser biopsico-social-espiritual.

No Brasil é cada vez mais nítido o interesse pela prática do tai chi chuan não só pela população mas também pelos meios acadêmico e governamental. A cada ano, além do tai chi chuan, outras técnicas vêm ganhando cada vez mais espaço dentro das políticas públicas de saúde promovidas pelo Governo Federal, crescendo o número de adeptos em todo o Brasil. No ano de 2006, o Ministério da Saúde, através da Política Nacional de Práticas Integrativas e Complementares (PNPIC), garantiu o acesso gratuito a essas práticas via o Sistema Único de Saúde (SUS), através da Portaria no 971 de 03/05/2006

A iniciativa de incluir práticas notadamente diversas das usuais em medicina no âmbito do SUS ganhou tamanha robustez que em nota publicada pela assessoria de imprensa do Ministério da Saúde, datada de 04 de janeiro de $2010^{4}$, só no ano de 2008 contabilizou-se um aumento de 358\% nas práticas corporais. Em 2011, o Ministério da Saúde lançou o Programa Academia da Saúde ${ }^{5}$, por meio da Portaria $n^{\circ} 719$ de 07/04/2011, com o intuito de criar espaços adequados para a realização de atividades individuais e coletivas, como o próprio tai chi chuan. Segundo informações oficiais, até o final de 2014 deverão ser implantados 4 mil polos para atender as metas das Políticas Nacionais de Atenção Básica e de Promoção da Saúde que integram o Plano de Ações Estratégicas para o Enfrentamento das Doenças Crônicas não Transmissíveis no Brasil, apresentado em setembro de 2011 durante a Assembleia da Organização das Nações

${ }^{3}$ BRASIL. Ministério da Saúde: Portaria $n^{\mathbf{0}} 971$ de 03 de maio de 2006. Disponível em < http://portal.saude.gov.br/portal/arquivos/pdf/PNPIC.pdf>. Acesso em: 01 ago. 2013.

${ }^{4}$ BRASIL. Ministério da Saúde: Práticas corporais no SUS. Disponível em < http://portal.saude.gov.br/portal/aplicacoes/noticias/default.cfm?pg=dspDetalheNoticia\&id_area=124\&CO_NOTICI A=11001>. Acesso em: 05 dez. 2012.

${ }^{5}$ BRASIL. Ministério da Saúde: Portaria $\mathbf{n}^{\mathbf{0}} \mathbf{7 1 9}$ de 07 abr. 2011. Disponível em: <http://portal.saude.gov.br/portal/aplicacoes/noticias/default.cfm?pg=dspDetalheNoticia\&id_area=124\&CO_NOTICI $\underline{\mathrm{A}=12400>}$. Acesso em: 05 dez. 2012. 
Unidas (ONU).

Particularmente no estado do Paraná, em reportagem veiculada pelo Jornal Gazeta do $\mathrm{Povo}^{6}$, o tai chi chuan é citado como umas das terapias alternativas que ganham destaque em consultas do SUS. Afirma a reportagem que as práticas corporais, só no ano de 2008, deram um salto de 12 mil para 149 mil praticantes. Ao observar esses números, não é possível deixar de questionar qual a razão para o interesse cada vez mais acentuado na prática do tai chi chuan por indivíduos que vivem sob um paradigma tão diverso do pensamento oriental. Além do ganho notadamente corporal, em termos de flexibilidade e saúde, que reflexões pode o tai chi chuan oferecer?

Conhecido por trabalhar a correlação entre a física moderna e o misticismo oriental, Capra (2006) destaca que há a ocorrência de insights intuitivos espontâneos em ambas as áreas. No misticismo oriental, contudo, a preparação da mente para uma consciência ampliada, não conceitual da realidade, silenciosa e meditativa, faz parte dessa cultura e é fruto da prática contínua. Lá os insights intuitivos não se limitam a momentos breves, mas se expandem, gerando uma consciência constante. Ao longo dos séculos, diversas técnicas, formas artísticas e rituais foram desenvolvidos com o fito de obter essa expansão.

Em seu livro A Espiritualidade do Corpo, Lowen (1997) afirma que o tai chi chuan tem como objetivo promover um senso de unidade com o cosmos através de movimentos fluidos e graciosos. Para ele, "a base da graciosidade e da verdadeira espiritualidade é a harmonia entre o ego e o corpo [...] a ioga ou o tai chi chuan refletem o interesse da pessoa pelos aspectos espirituais do corpo" (LOWEN, 1997, p. 22-23).

Assim, o artigo está construído da seguinte forma: a primeira parte propõe uma visão genérica do modelo dualista ocidental, de modo a conduzir o leitor a perceber sua própria inserção no mundo cartesiano e da sua condição secular, apresentando-lhe a hipótese de ser o tai chi chuan uma alternativa para a reconstrução de um caminho para o sagrado; a segunda parte propõe apresentar ao leitor a técnica de tai chi chuan, sua composição trinária entre marcialidade, ginástica e religiosidade, a leitura simbólica da cosmogonia chinesa e seu impacto no microcosmo corporal e psíquico do praticante; a terceira parte, relativa ao combate ao dualismo pela experiência mística do sagrado, propõe apresentar o tai chi chuan como um meio de proporcionar uma transformação

6 TERAPIAS alternativas ganham destaque em consultas no SUS. Gazeta do Povo, Curitiba, 22 mai. 2013. Caderno Vida e Cidadania, p. 4. 
realmente ontológica a partir do surgimento de um espaço psíquico e sagrado interno no praticante, de unificação da dualidade e de reconexão com seu self; através de um breve enfoque alquímico proporcionado pelos conceitos de psicologia analítica, a quarta parte busca traduzir o que se entende por alquimia interna e união mística, expressões usuais na prática do tai chi chuan e sua convergência dentro do processo de unificação de dualidade a partir da replicação ritualística da cosmogonia como meio de alcançar a essência da transcendência; por fim, a conclusão se encaminhará para o entendimento de que o tai chi chuan, além dos ganhos notadamente fisiológicos, é uma arte marcial que traz em seu bojo uma poderosa metáfora alquímica capaz de conduzir o praticante a estados modificados de consciência. Contudo, ele deverá vencer o desafio egoico, superar a compreensão cartesiana e dicotômica entre mente e corpo para então voltar sua atenção para o seu rico e desconhecido interior.

\section{0 Modelo dualista ocidental}

Após a Revolução Industrial e a Revolução Francesa, fruto do movimento racional iluminista, a humanidade viu nascer o regime capitalista, que modificou completamente o modelo de vida até então conhecido, dando espaço ao surgimento da modernidade. De tempos mais lentos, de produção exclusivamente manufatureira, o novo modelo de mercado deu espaço para a acelerada cultura de massas e de consumo desenfreado, gerando subprodutos psicopatológicos de dimensões globais.

As teorias mecanicistas que sustentam a física clássica moldaram o pensamento ocidental nos últimos séculos; o pensar científico surge com todo o seu esplendor, rompendo a escuridão de um mundo teocêntrico e supersticioso, proporcionando à humanidade um progresso em escala jamais antes vista ou imaginada. $\mathrm{O}$ pensamento científico induz o raciocínio à linearidade, à fragmentação e ao reducionismo. No entanto, esse entendimento provocou uma dissociação, desenvolvendo um pensamento que, "dividindo em dois reinos diferentes a mente e a matéria, tem levado o homem ocidental a igualar sua identidade apenas à sua mente, em vez de igualá-la a todo o seu organismo" (CAPRA, 2006, p. 25). A identificação única com a consciência produz um pensamento unilateral e perigoso. Segundo Jung:

A dessacralização de nossa época tão profana é devida ao nosso desconhecimento da psique inconsciente e ao culto exclusivo da 
consciência. Nossa verdadeira religião é o monoteísmo da consciência, uma possessão da consciência que ocasiona uma negação fantástica da existência de sistemas parciais autônomos [...]. Isto representa um grande perigo psíquico, pois os sistemas parciais se comportam como quaisquer outros conteúdos reprimidos [...]. Tal fato, evidente nos casos de neuroses, também o é no campo dos fenômenos psíquicos de caráter coletivo (JUNG, 2011a, v. 13, p. 42).

O processo de secularização afastou os dogmas religiosos do processo racional. Consequentemente, como um efeito colateral, lançou as experiências místicas, que eram até então equivocadamente monopólio da religião, à margem da ciência (TERÊNCIO, 2007). De acordo com Eliade [198-], a conexão com o sagrado paulatinamente desapareceu e, em contrapartida, surgiu uma visão pessimista de existência, e o tempo cíclico se tornou algo insustentável, pois desprovido de sentido, transformando-se exclusivamente em profano.

Porém, com o surgimento das bases da física quântica, do processo de globalização, do movimento de contracultura, a concepção oriental vem se popularizando cada vez mais no ocidente, e as mais diversas técnicas e filosofias orientais passaram a ser estudadas e praticadas. "A preocupação crescente com a ecologia, o forte interesse pelo misticismo, a progressiva conscientização feminista e a redescoberta de acessos holísticos à saúde e à cura são manifestações da mesma tendência evolucionária” (CAPRA, 2006, p. 17). Há, portanto, a existência de um movimento da humanidade de busca por uma visão mais orgânica e unificada da vida.

A religião, aqui entendida na acepção própria da palavra e não no seu sentido institucional, tem como significado literal religar, restabelecer a conexão do homem e seu mundo profano ao mundo sagrado das divindades (CHAUÍ, 2000) e encontra-se cada vez mais ausente da vida do homem ocidental não religioso (ELIADE, [198-]). Este se vê cada vez mais sozinho em seu espaço interno profano, tornando sua existência empobrecida, na qual não há lugar para a vivência do sagrado, do místico. Ao afastar o espírito místico da reflexão filosófica, o pensamento racional afastou do homem o sentido de totalidade, tornando-o unidimensional, razão da sua permanente angústia (OLIVEIRA, 2009). As pessoas, quando afastadas da natureza, são dominadas pelo ego, sentem-se sozinhas e tornam-se hostis, violentas, torturam-se com sentimentos como ódio, cobiça e fúria, não percebendo que estão a ferir a si mesmas (COOPER, 1989). 
Esse indivíduo solitário, culturalmente adaptado ao pensamento cartesiano, encontra-se cada vez mais desejoso em vivenciar o seu próprio ser anímico. Contudo, ainda muito condicionado e desconfiado de tudo que possa ser considerado nãocientífico para os padrões ocidentais, "colocando entre aspas a 'sabedoria' oriental, remetendo-a para o domínio obscuro da crença e da superstição" (JUNG, 2011a, p. 15).

Independentemente das diferenças culturais e dos receios de origem obscura, fato é que o pensamento místico oriental ganha cada vez mais espaço no mundo ocidental, contrapondo e compensando o ressecamento espiritual decorrente do processo de secularização, demonstrando compatibilidade com o prognóstico de Eliade [198-, p. 63]: "mais tarde, teremos ocasião de nos perguntarmos se esta secularização da Natureza é realmente definitiva, se não há nenhuma possibilidade, para o homem não religioso, de reencontrar a dimensão sagrada da existência no mundo".

Portanto, a hipótese é de que, dentro do contexto assinalado, o tai chi chuan, técnica chinesa de combate que busca desenvolver em seus praticantes atributos físicos e mentais para a luta - seja ela de ordem física ou psíquica - surge como caminho alternativo para a ressacralização do homem ocidental que se interessa por sua prática contínua. A repetição dos movimentos, sua circularidade, sua simbologia, reproduzem o pensamento místico cosmogônico chinês de retorno ao princípio fundamental unificador de todas as coisas (o Taiji) e "é graças a este 'eterno retorno' às fontes do sagrado e do real que a existência humana lhe parece salva do nada e da morte" (ELIADE, [198-], p. 119). O sagrado permite a integração do homem ao ecossistema que o rodeia, restituindo-lhe sua natureza sistêmica, que é imperceptível através da consciência de base racional e cartesiana.

\section{O pensamento chinês e o tai chi chuan}

Mesmo aquele que nunca praticou um movimento sequer de tai chi chuan possivelmente terá uma representação imagética internalizada de sua coreografia. Certamente não deixará de resgatar aquela imagem pitoresca de um parque em uma manhã fria, com uma leve névoa envolvendo um grupo de pessoas que, em respeitoso e sagrado silêncio, executa movimentos suaves, lentos e cadenciados. Contudo, desde já uma ressalva: Gaffney e Siawn-Voon Sim (2009) esclarecem àqueles que estão atraídos pela técnica que inobstante a graciosidade dos movimentos seja sua característica mais 
visível, o tai chi chuan é uma arte marcial, uma técnica criada para desenvolver nos praticantes atributos físicos e mentais para o combate.

Tai chi chuan se traduz como o "boxe da Suprema Cumeeira", "a arte do combate do Taiji" (DESPEUX, 1981, p. 11) ou ainda "punho supremo" (SHAHAR, 2011, p. 195), sendo o taiji, ou tai chi, a unidade suprema, o primeiro princípio que rege o universo e preside o yin e o yang, normalmente traduzido como a cumeeira, o eixo em que se ordenam as dez mil transformações, que dá origem a todos os seres e coisas manifestos (PAGE, 1995). Shahar (2011), ao estudar as modalidades marciais desenvolvidas na China no final do século XVII, traduz o termo quan como "combate de mãos" e define o tai chi chuan como uma arte que combina técnicas de combate de mãos livres com métodos meditativos e fisiológicos taoístas que se desenvolveram nas proximidades do mosteiro Shaolin, berço do Kung-Fu (Wushu) e do budismo Chan (Zen), dele certamente recebendo influências.

Assim como outras técnicas de combate de mãos livres do mesmo período, o tai chi chuan se caracteriza também por se tratar de uma "síntese única de metas marciais, terapêuticas e religiosas (...) descritas por um rico vocabulário de autocultivo fisiológico e espiritual (...)" (SHAHAR, 2011, p. 201). Isso ocorreu porque a ginástica conhecida como Daoyin, praticada há milênios na China, uma combinação de movimentos e técnicas respiratórias para desenvolver a energia interior (chi), promover a cura, a prevenção de doenças e a longevidade do corpo, foi incorporada às práticas taoístas, tornando-se parte de um sistema religioso voltado à obtenção da imortalidade, "e serviu como veículo para o impacto dessa religião sobre as artes marciais" (SHAHAR, 2011, p. 202).

A ginástica Daoyin em muito se assemelha a técnicas corporais e respiratórias antigas que não raro remetem até mesmo a Huang $D i$, emblemática figura chinesa conhecida como o Imperador Amarelo (2698-2599 a.C.) ao qual se atribui a concepção do livro Neijing, ou "energia interna do tai chi" (GAFFNEY E SIAWN-VOON SIM, 2009, p. 14), sobre medicina tradicional chinesa. Para Cooper (1989), as técnicas de magia e misticismo atribuídas a esse lendário personagem poderiam estar nas origens de um Taoísmo primitivo, afastadas por Lao Tzu e Chuang Tzu por ocasião do surgimento do Taoísmo clássico em aproximadamente 600 a.C., e resgatadas no Taoísmo decadente (COOPER, 1989) durante o período medieval chinês, caracterizado pela associação de 
práticas psicofisiológicas (alquimia interior) e pela ingestão de drogas (alquimia operatória) com o fim de atingir a imortalidade do corpo (DESPEUX, 1981).

Os refinados ensinamentos metafísicos de Lao Tzu e existentes no Tao Te Ching (o livro das Mutações) correspondentes ao Taoísmo clássico, por outro viés, são focados objetivamente apenas na compreensão filosófica e na adoção de um comportamento que prega o "afastamento de tudo quanto seja artificial, sofisticado e inútil" (COOPER, 1989, p. X). O objetivo continua sendo a busca pela composição entre o yin e o yang, agora a partir da adoção de uma postura filosófica, na compreensão de que o mundo está continuamente sob a alternância desses dois princípios: "quando domina o yang é a atividade, a fecundidade, a luz, o calor, a riqueza - primavera e verão; quando é $o$ yin que domina, é a passividade, a obscuridade, o frio, a umidade - outono e inverno" (LE GOFF, 1990, p. 336).

Despeux (1981, p. 42), citando Zhou Dunyi, descreve o princípio do Tai Chi da seguinte forma: “o Taiji põe-se em movimento e produz o Yang. Quando o movimento atinge seu apogeu, segue-se-lhe o repouso. Atingindo o seu apogeu, o repouso, volta o movimento. Repouso e movimento se alternam, pois cada qual é a raiz do outro. Há separação do Yin e do Yang, e os dois princípios são estabelecidos”. Da transformação emergem os cinco elementos, os oito trigramas e, por fim, as dez mil coisas.

Da dinâmica do movimento (chi) das mutações entre os polos (yin e yang) é que o equilíbrio e a harmonia devem ser obtidos, tanto no próprio homem como no mundo, até que os dois sejam um e se traduzam no Tao (COOPER, 1989).

Para atingir a harmonia com o Tao, deve-se transformar o chi individual, grosseiro e fraco, em chi sutil e forte (PAGE, 1995). O chi é, para os chineses, a unidade central de uma força cósmica que envolve todo o cosmos, é o princípio da mutação, é o próprio movimento que permite a circulação e o dinamismo do sistema. "No oriente também existe uma série de conceitos semelhantes, como o shakti ou energia do espírito, a kundalini ou a força da serpente, e ainda o calor do espírito ou força do espírito, dos tibetanos" (PAGE, 1995, p.11). Dessa forma, os taoístas buscavam aumentar a própria vitalidade, absorvendo o chi cósmico primordial, transformando o chi individual, o que não só dinamiza e cura o organismo como também anima as funções superiores da mente (PAGE, 1995).

No caso do tai chi chuan, a busca pela perfeita circulação do chi no organismo 
do praticante é o objetivo da técnica, tanto para fins de combate efetivo quanto para fins de saúde e fins metafísicos (SHAHAR, 2011). Assim, ao associar o princípio do tai chi ao corpo humano, o tai chi chuan proporciona ao praticante, através do rito, a harmonização do microcosmo do seu corpo à medida que se põe em harmonia com o universo (DESPEUX, 1981).

\section{0 combate ao dualismo pela experiência mística do sagrado}

A visão dualista e compartimentada não decorre unicamente da visão newtoncartesiana do mundo. Há outro aspecto a ser considerado. De acordo com Jung (2011b), a educação anímica do homem ocidental difere muito da educação anímica do homem oriental, pois em nossa cultura prevalece a exigência da imitatio Christi, havendo o entendimento de que todos os cristãos se tornem semelhantes à figura de Cristo. Porém, a visão dualista sujeito-objeto, que atua como uma bússola internalizada, acaba por colocar o modelo como um objeto externo de adoração, afastando-o da experiência anímica de totalidade.

Ao depositar no modelo todos os valores, positivos e negativos, o homem ocidental afasta de si a responsabilidade e a vivência anímica da experiência mística. Sua alma é esvaziada de sentido, pois a totalidade, o si-mesmo, encontra-se fora, conquanto que para o homem oriental não há nenhuma divisão ou exclusão. Assim, para o homem ocidental, há uma desvalorização da alma, um sentimento de menos-valia associado a ela. "Quem quer que fale da realidade da alma será censurado por seu 'psicologismo' [...]. É quase uma blasfêmia pensar que uma vivência religiosa possa ser um processo psíquico" (JUNG, 2011b, p. 20-21).

Por tal razão, identifica-se no discurso junguiano uma forte preocupação com a mera imitatio de um modelo ou uma técnica oriental por um ocidental. Por analogia, toma-se de empréstimo a leitura paralela do seu artigo "A ioga e o Ocidente", no qual Jung (2011c) afirma categoricamente que a tentativa de um ocidental de obter a mesma experiência de um iogue hindu seria improvável, já que a civilização ocidental ainda é muito nova e deveria primeiramente treinar o seu consciente, livrando-se de suas unilateralidades bárbaras antes de “imitar métodos que surgiram em condições psicológicas totalmente diversas" (JUNG, 2011c, p. 76). Em outra passagem de sua obra, Jung utiliza-se de um aforismo chinês para reafirmar claramente sua preocupação, 
citado no livro alquímico chinês O Segredo da Flor de Ouro: "Se o homem errado usar o meio correto, o meio correto atuará de modo errado" (JUNG, 2011b, p. 15). Assim, pela razão junguiana, há que sempre se manter alerta ao autoengodo gerado pela superficialidade. Uma vez considerada a ressalva e o salutar aviso para o perigo da imitatio, a prática do tai chi chuan pode inspirar o ocidental a vivenciar uma experiência de totalidade, toda própria, única, resultado da combinação de sua cultura científica e de suas sufocadas necessidades anímicas.

Mais do que a soma das suas partes, o tai chi chuan deve ser considerado em sua totalidade. Tang Hao, citado por Shahar (2011, p. 217) exemplifica esse entendimento assim afirmando: "no treinamento de Taiji Quan, os três aspectos de consciência, movimento e respiração são harmoniosamente integrados. A aproximação holística do treinamento e a ênfase sobre a unidade externo-interno são a característica da prática do Taiji Quan". Dessa maneira, o retorno ritualístico ao Tao (si-mesmo) através da prática do tai chi chuan é o mesmo que buscar na fonte da totalidade a segurança ontológica perdida (GUSDORF, 1980).

Não obstante o contraste com o pensamento dualista cartesiano, é cada vez maior a integração entre o pensamento chinês e os novos rumos para o pensamento ocidental. O pensamento linear indutivo tem se revelado cada vez mais insuficiente para sustentar e desenvolver as novas ideias em diversas áreas, bem como para compreender e estudar a riqueza do espectro das experiências humanas, inclusive as místicas, ainda consideradas desprezíveis pelo paradigma vigente (BATESON, 1998). O pensamento oriental nunca separou o espírito e a matéria (SHAHAR, 2011), e o homem é entendido como um microcosmo que, por analogia, representa o macrocosmo (DESPEUX, 1981; PAGE, 1995; JUNG, 2001).

Assim, a chamada teoria ecológica da mente de Gregory Bateson e sua compreensão sistêmica de que a menor parte de alguma coisa contém o todo dentro de si vem ensejando a construção de um modelo integrado de pensamento que guarda correspondência com a unidade entre o homem e seu equivalente cósmico no pensamento oriental chinês. Cooper (1989) expressa o mesmo entendimento sistêmico ao afirmar que aqueles que ganham consciência de que não só são parte de um todo, como também são o todo em si mesmo, ampliam a percepção e a valorização da vida em todas as suas expressões. 
Segundo Oliveira (2012), o conceito de mente ecológica criado por Bateson tem como ênfase a percepção do real como uma experiência imediata através da intuição; a experiência do sagrado, do numinoso, é de integração, entendimento este que claramente se opõe à estrutura do racionalismo cartesiano e seus princípios dualísticos: mente-corpo, sujeito-objeto.

Ademais, um pensamento cada vez mais ecológico, possibilita o florescimento de experiências de integração que não nega os avanços da modernidade, mas que recupera e possibilita "perspectivas dialógicas e trans-lógicas" entre ciência e espiritualidade (OLIVEIRA, 2009, p. 24) e abre espaço para experiências de cunho numinoso, não racionais, traduzidas como "momentos e estados psíquicos de solene devoção e arrebatamento" (OTTO, 2007, p. 40).

Ainda, tendo por base os ensinamentos de Mircea Eliade sobre a função ritual na constituição geográfica do espaço sagrado pelo homem religioso, no rito cosmológico do tai chi chuan há uma demarcação territorial psíquica, o surgimento de um espaço interno sagrado para reconexão com o si-mesmo (self). O princípio do tai chi decorre a noção de eixo no qual se ordenam as dez mil transformações, eixo este que corresponde ao axis mundi que Eliade [198-] associa ao momento sagrado cosmológico de fundação ontológica do mundo, do estabelecimento de uma ordem no caos. Os movimentos fluídicos e circulares que o praticante de tai chi chuan realiza transformam-no em um pivô sobre o qual ele observa silenciosamente as alternâncias entre yin e yang (DESPEUX, 1981), conectando o céu e a terra, o sagrado e o profano, permitindo o surgimento, para o homem cartesiano e secular, o sentimento sagrado de conexão.

Sob esse prisma, o tai chi chuan é um ritual pelo qual o praticante, à medida que incorpora respiração, movimento e concentração, busca alcançar a suprema cumeeira, o seu axis mundi interior, o eixo sobre o qual todas as transformações se dão. E é através desse ritual que se dá o caminho para o princípio ordenador do mundo - o Tao - à medida que reproduz a cosmogonia chinesa em um processo de reordenação do universo interno a partir do trabalho corporal e psíquico:

A rotina de treinamento era aberta na quietude do taiji primordial, caminhava pela evolução interna de yin e yang, pelos cinco elementos e oito trigramas e seguia até a profusão inumerável de fenômenos. Ao invés de estacionar nesse estado de multiplicidade, o artista marcial, então, voltava ao tempo da origem do universo, partindo da miríade de fenômenos aos oito trigramas, voltando aos dois princípios cósmicos 
yin e yang e culminando na tranqüilidade do taiji. (SHAHAR, 2011, p. 228).

Sendo assim, a abertura do ocidente para a prática de terapias orientais é um sinal do reaparecimento do sagrado, do religioso, do mistério, cuja característica é a busca pela necessidade contemplativa e a consequente emersão de valores como gratuidade, espiritualidade e redescoberta da relação homem-natureza (BINGEMER, 1998), o que, no sentido marcial do tai chi chuan, corresponde justamente ao combate ao dualismo por séculos cultural e psiquicamente praticado.

\section{A união mística}

A paulatina aproximação das técnicas de combate e a medicina chinesa decorrem da necessidade de teorização que surge no final do período Ming - 1368 a 1644 d.C. (SHAHAR, 2011). Dessa dialética surge a densa combinação, uma união aparentemente inimaginável entre dois pontos paradoxais como a marcialidade e a religiosidade. Superando a aparente incompatibilidade e relacionando-os a partir da compreensão do equilíbrio entre opostos, vê-se aqui também a replicação da mútua interação entre aspectos de natureza diferentes e complementares, como se dá entre o yin e o yang.

Shahar (2011) explica que a partir do século XVII, o vocabulário da cosmologia chinesa se mistura com a descrição das técnicas de combate, enriquecendo-as com noções de alquimia interna taoísta de união mística. No Neidan, a alquimia interior, voltada para o trabalho do sopro, tendo a inspiração associada ao yin e a expiração ao yang, a transmutação energética se dá no "campo de cinábrio", abdômen, coração e cabeça, "sendo o cinábrio um sulfeto de mercúrio e a matéria-prima dos alquimistas chineses" (DESPEUX, 1981, p. 59).

Citando Chang Naizhou, Shahar esclarece que a transmutação energética no campo de cinábrio se dava da seguinte forma: "a primeira, de refinar a essência (jing) e transmutá-la em respiração (chi); a segunda, de refinar a respiração e transmutá-la em espírito (shen); e a terceira, de refinar o espírito e fazer com que ele retornasse ao vazio primordial (xu)" (SHAHAR, 2011, p. 229). A partir desse processo interno era produzido o elixir responsável pelo poder marcial.

Tão interessante quanto a obtenção de poder marcial a partir da transmutação 
alquímica energética ocorrida no organismo é a transmutação da mesma energia em energia espiritual (DESPEUX, 1981), muito mais refinada e direcionada para o pensamento criador, o elo entre o corpo e o espírito. Quando o praticante alcança esse nível de transmutação alquímica, ele "perde a consciência do eu e do corpo [...] encontra-se num estado que ultrapassa a dualidade consciência/não consciência, pois foi realizada a união dos contrários: interior e exterior, movimento e repouso, eu e o outro [...] O praticante não executa por si mesmo os movimentos, deixa operar o Tao dentro de si” (DESPEUX, 1981, p. 72).

Em razão do entendimento cada vez mais alquímico dos processos interiores que se dão na psique do praticante assíduo de tai chi chuan, de modo reducionista e incipiente, pode-se traduzir o Tao por "caminho" e se entende por ser o Um, o Todo, que está além da mente racional e só pode ser entendido por indução (COOPER, 1989). Nesse sentido, Jung afirma que o conteúdo psicológico do conceito de Tao é de justamente unir o separado, numa espécie de indicação alquímica para a geração de uma consciência iluminada: "para isso, é necessário um 'aquecimento', ou seja, uma elevação da consciência, a fim de que a morada da essência espiritual seja 'iluminada'. A união de ambas produz a "vida consciente"” (JUNG, 2001, p. 37) ou, nas palavras de Despeux (1981), o pensamento criador.

Citando o Tao Te Ching, Cooper (1989, p.53) afirma: “"o Tao gera o um, o um gera o dois, o dois gera o três, o três gera todas as coisas. As dez mil coisas são geradas pelo Tao, mas existem dentro do Tao"'. Na alquimia ocidental, a mesma ideia ganha correspondência no aforismo de Maria Prophetissa: "Um torna-se Dois, o Dois torna-se Três e do três provém um que é o quarto" (JUNG, 2011b, p. 34). No Tai Chi Chuan, o praticante refaz o processo de diferenciação cósmica apenas para revertê-lo e assim atingir a união mística com o Supremo Absoluto (SHAHAR, 2011). A união dos opostos, segundo Jung (2011b), num nível mais alto da consciência, não é uma questão de vontade que passa pela mente racional. Trata-se de um desenvolvimento psíquico, razão pela qual alerta insistentemente para os perigos gerados pela imitação consciente.

Para Cooper (1989), reconciliar a dualidade e atingir a unidade é necessário para o pensamento notadamente cartesiano. Se não houver relação, há apenas a inércia, a estagnação. Sua compreensão é de que onde existem relações em dualidade, o terceiro mediador é necessário para salvar as duas forças da tensão interna. No Taoísmo, as 
forças duais equivalem ao yin e o yang, e quando o terceiro mediador é introduzido, há o retorno da dualidade à unidade. "Esta coincidência de opostos é sempre um movimento interior, simbolicamente dentro do recipiente transformador, o ser interior" (COOPER, 1989, p. 94). A China nunca se afastou dos fatos centrais da alma a ponto de focar no desenvolvimento unilateral de uma função psíquica isolada. "Os opostos sempre se equilibram na mesma balança - sinal de alta cultura. Ainda que represente uma força propulsora, a unilateralidade é um sinal de barbárie” (JUNG, 2001, p. 27).

A união mística entre yin e yang para o retorno ao Tao, ao uno, guarda correspondência a coniunctio oppositorum, uma das etapas da alquimia ocidental, cujo sentido psíquico foi bem explorado por Jung. A coniunctio representa a união interior de elementos masculinos e femininos para a totalidade psicológica e espiritual. É o plano mais elevado da integração psicológica, que resulta no encontro com o si-mesmo (self), o arquétipo da totalidade (JUNG, 2011b).

Entendendo, portanto, o tai chi chuan como uma arte marcial que se utiliza de exercícios taoístas com vistas a atingir o equilíbrio através da replicação constante de movimentos que contém em si a encenação cosmogônica da criação do universo, o árido pensamento ocidental cartesiano e secular, fragmentado em mente/corpo, difere totalmente da essência taoísta. "No contexto da cultura chinesa, a libertação taoísta significava, mais especificamente, uma libertação das regras rígidas da convenção" (CAPRA, 2006, p. 90). Por fim e nesse sentido, Cooper (1989) arremata concluindo que nenhum conhecimento místico pode ser obtido por intermédio da separação entre o isto e o aquilo, pois sua essência está justamente na transcendência entre todas as dualidades, até o reino unificado e indiferenciado.

\section{Considerações finais}

O tai chi chuan é uma arte una e trina: marcialidade, alquimia e a corporalidade unem-se para formar uma joia com que a cultura chinesa presenteia o ocidente. A depender do perfil de cada praticante, uma ou ambas as facetas do tai chi chuan podem ser exploradas para se alcançar aquilo que desejar, da flexibilidade corporal à transcendência, não há limites para a colheita de resultados.

O olhar ocidental que analisa e cataloga o mundo para poder compreendê-lo acaba por nos remeter a um interessante aforismo chinês: "da discriminação entre isto e 
aquilo, um exército de demônios se inflama". (COOPER, 1989, p. 117). Curiosamente, em uma rápida associação, Despeux (1981, p. 17) alude para o fato de que "no princípio, o Taiji quan, pouco divulgado em Xangai, era até desprezado, pois lhe chamavam a 'técnica de combate com os demônios' (nie gui quan), e seus adeptos o praticavam mais ou menos escondidos". Provavelmente isso se deve ao fato de que, conforme a mesma autora, a famosa escola taoísta do monte Wudang teria desenvolvido uma série de rituais militares de exorcismo para serem realizadas em cerimônias de combate (DESPEUX, 1981). Longe de se trilhar a explicação metafísica para o termo, é preferível realizar uma associação metafórica que poderia considerar o dualismo cartesiano como o verdadeiro "demônio" a ser superado e transcendido.

Em se tratando de uma arte marcial, o tai chi chuan é considerado integrante do que os chineses denominam de wushu (arte guerreira), no ocidente mais conhecido como kung-fu, cuja tradução é maestria, habilidade, e "ao associar maestria à superação do 'Falso Ego', o termo se aproxima da visão oriental de transcendência" (APOLLONI, 2004, p. 54). E é justamente o aspecto da transcendência que alça o tai chi chuan como um meio capaz de conduzir o praticante ocidental à superação do dualismo cartesiano que norteia seu modus vivendi contemporâneo e secular, que traz consigo o notável desenvolvimento científico à custa, contudo, de um ressecamento espiritual que o afasta da sua humanidade e favorece o surgimento de patologias físicas, psicopatologias e crises existenciais.

Dessa forma, o tai chi chuan configura-se em uma técnica de combate ao dualismo, à superação do ego e da racionalidade cartesiana, de modo a (re)criar um espaço sagrado dentro do indivíduo, (re)organizando o caos interior. Ainda, emprestando a terminologia demonológica, poder-se-ia ir além, sugerindo que através do rito do tai chi chuan é possível superar o demônio da razão, aquilo que representa o aspecto escuro, desconhecido e unilateral e que, de algum modo, aterroriza e subjuga o homem. Uma vez "exorcizado" de seu próprio demônio dualístico e tendo permitido a unificação de opostos neste espaço sagrado obtido em seu íntimo, pode-se alcançar uma verdadeira experiência do sagrado.

Contudo, é preciso considerar que a postura oriental sempre foi a da valorização do ser em detrimento do ter, da possibilidade de se alcançar a harmonia e o equilíbrio através de técnicas que permitam uma ponte entre o visível e o invisível, entre o corpo e 
a alma, o que muito seduz o dissociado homem ocidental e sua árida rotina. Uma vez mais o alerta junguiano de que o caminho é árduo, pois é preciso enfrentar uma verdadeira transmutação alquímica caso se deseje beber realmente dessa fonte. Para tanto, faz-se necessário ir além da reprodução, vício característico da cultura europeia e latina, que elege um modelo externo como objeto de culto e que impede o homem de "atingir as profundezas da alma a fim de transformá-la naquela totalidade que corresponde ao modelo" (JUNG, 2011b, pg. 19).

Vencido o desafio egoico e superados os véus da prática superficial e do risco do modismo coletivo, favorecido ainda por um modelo paradigmático em desenvolvimento que permite cada vez mais o diálogo entre ciência e espiritualidade, o praticante pode então voltar sua atenção para o seu interior, individuando-se a partir da imersão em suas dimensões mais complexas não observáveis conscientemente pelo grande público orientado quase sempre pela dicotomia mente/corpo. Superada a dualidade, alcança-se a vida consciente, "ou, como dizem os chineses: a realização do Tao" (JUNG, 2001, p. $37)$.

Conclui-se, assim, que o tai chi chuan emerge como alternativa ao homem ocidental não religioso, não somente como comprovado método de saúde corporal mas também como meio de possibilitar a reaproximação do sagrado em seu espaço interno profano e de possibilitar a obtenção de harmonia e equilíbrio psíquico. A prática reiterada do tai chi chuan traz em si o potencial de conduzir seu praticante a dimensões mais profundas de si mesmo, abrindo espaço para experiências de cunho numinoso, não racionais.

\section{Referências}

APOLLONI, R.W. "Shaolin à Brasileira": Estudo sobre a presença e a transformação de elementos religiosos orientais no Kung-Fu praticado no Brasil. Dissertação (Mestrado). Ciências da Religião, Pontifícia Universidade Católica de São Paulo, São Paulo, 2004. Disponível em < http://www.shaolincuritiba.com.br/disserta apolloni.pdf > Acesso em: 11 jun. 2013.

BATESON, G. Pasos hacia uma ecologia de la mente - uma aproximacion revolucionaria de la autocompresión del hombre. Buenos Aires: Edicionies Lohlé-Lumen, 1998.

BINGEMER, M. C. L. A Sedução do Sagrado. In: CALIMAN, SDB, Pe. Cleto. (Org.). A Sedução do Sagrado. O Fenômeno Religioso na Virada do Milênio. Petrópolis: Vozes, 1998, p. 79.

CAPRA, F. O Tao da Física. Um Paralelo entre a Física Moderna e o Misticismo Oriental. São Paulo: Ed. Cultrix, 2006.

CHAUÍ, M. Convite à filosofia. São Paulo: Ed. Ática, 2000.

COOPER, J.C. Yin \& Yang. A Harmonia Taoísta dos Opostos. São Paulo: Ed. Martins Fontes, 1989. 
DESPEUX, C. Tai Chi Chuan. Arte Marcial, Técnica de Longa Vida. São Paulo: Círculo do Livro, 1981.

ELIADE, M. O Sagrado e o Profano. A Essência das Religiões. Coleção Vida e Cultura. Ed. "Livros do Brasil" Lisboa, [198-].

GAFFNEY, D.; SIAW-VOON SIM, D. A Essência do Tai Ji Quan. Tradução Gabriela Morgado. Ed. Blurb, 2009.

GUSDORF, G. Mito e metafísica. Introdução à filosofia. Tradução Hugo di Prímio Paz. São Paulo: Editora Convívio, 1980.

JUNG, C. G. Psicologia do inconsciente. 17ª ed. Petrópolis, RJ: Vozes, 2007.

. Estudos alquímicos. O.C., v. 13, $2^{\text {a }}$ ed., Petrópolis, RJ: Vozes, 2011 a.

Psicologia e alquimia. O.C., v. 12, 5 a ed., Petrópolis, RJ: Vozes, $2011 \mathrm{~b}$.

A ioga e o Ocidente. In: Psicologia e Religião Oriental. O.C., v. 11/5, 8 ed., Petrópolis: Vozes, 2011c, p. 76.

LE GOFF, J. História e memória. Tradução Bernardo Leitão, et al, Campinas, SP: Editora da UNICAMP, 1990.

LOWEN, A. A Espiritualidade do Corpo. Tradução Paulo Cesar de Oliveira. São Paulo: Cultrix, 1997.

PAGE, M. Ch’i: Energia Vital. Tradução Beatriz Sidou. São Paulo: Pensamento, 1995.

OLIVEIRA, V. L. de. A Mística do Sagrado no Toque dos Chakras. Curitiba, PR: Protexto, 2009.

A representação do espaço sagrado em estados de êxtase no pensamento místico indiano. Raega - O Espaço Geográfico em Análise. [S.I]. v. 27, jan. 2013. Disponível em: < http://ojs.c3sl.ufpr.br/ojs2/index.php/raega/article/view/30425/19707> Acesso em: 12 jun. 2013.

OTTO, R. O sagrado: os aspectos irracionais na noção do divino e sua relação com o racional. Traduzido por Walter O. Schlupp, São Leopoldo: Sinodal/EST; Petrópolis: Vozes, 2007.

SHAHAR, M. O Mosteiro de Shaolin: história, religião e as artes marciais chinesas. Tradução: Rodrigo Wolff Apolloni e Rodrigo Borges de Faveri. São Paulo: Perspectiva, 2011.

TERÊNCIO, M. G. Um percurso psicanalítico pela Mística, de Freud a Lacan. Florianópolis, 2007. Conclusão de Mestrado, UFSC. Disponível em < http://repositorio.ufsc.br/xmlui/handle/123456789/89795> Acesso em 10 ago. 2013.

Recebido: 06/04/2014

Received: 04/06/2014

Aprovado: 19/07/2014

Approved: 07/19/2014 